\title{
Merger of Tropical Cyclones Zeb and Alex
}

\author{
Hung-Chi Kuo, George T.-J. Chen, and Chung-Hsien Lin \\ Department of Atmospheric Sciences, National Taiwan University, Taipei, Taiwan
}

(Manuscript received 2 February 1999, in final form 1 December 1999)

\begin{abstract}
The merger of tropical cyclones Zeb and Alex is described. The process includes mutual cyclonic rotation, followed by merger of Zeb and Alex. The cyclonic rotation of Alex around Zeb accelerated as the separation distance decreased to $850 \mathrm{~km}$. During the merger process, Alex was quickly elongated and wrapped cyclonically around Zeb to become a spiral band of Zeb. The final merger occurred at a distance of $450 \mathrm{~km}$. The observed merger processes appear to be in good agreement with the potential vorticity theories of vortex interaction and the formation of spiral bands. Despite the presence of moist convections, the straining-out regime of Dritschel and Waugh appears to be applicable to the interaction between Alex and Zeb.
\end{abstract}

\section{Introduction}

Spiral rain bands are one of the most noticeable features associated with tropical cyclones. They have been observed to move slower than the local mean tangential flow (Senn and Hiser 1959). There have been many theoretical studies on hurricane spiral bands. It appears that the theories can be grouped into three general classes, namely, gravity wave theories (e.g., Kurihara 1976; Willoughby 1978), boundary layer asymmetry theories (e.g., Fung 1977; Shapiro 1983), and potential vorticity theories (e.g., Guinn and Schubert 1993; Montgomery and Kallenbach 1997; Montgomery and Enagonio 1998). The gravity wave theories view the spiral bands as regions of upward motion and condensation caused by propagating internal gravity waves. The boundary layer asymmetry theory of Fung (1977) proposes that the spiral structures within hurricanes are produced through the instability of boundary layer flow fields. In particular, her results indicate a nearly stationary spiral structure with respect to the hurricane center for the most unstable mode. On the other hand, Shapiro's model (1983) does not involve dynamic instability but illustrates how quasi-stationary bands can stem from an axisymmetric, moving low pressure field in the boundary layer. Guinn and Schubert (1993) divided spiral bands into two classes: outer bands and inner bands. The outer bands may stem from nonlinear effects during the breakdown of the intertropical convergence zone (ITCZ)

Corresponding author address: Dr. Hung-Chi Kuo, Dept. of Atmospheric Sciences, National Taiwan University, 61, Ln 144, Sec 4 Keelung Road, 10772 Taipei, Taiwan.

E-mail: kuo@lanczos.as.ntu.edu.tw through barotropic instability. The inner bands may stem from the vortex merger and axisymmetrization processes associated with the interaction of two or more unequal vortices. As merger occurs, the potential vorticity patch of the weaker vortex is quickly elongated and wrapped around the stronger vortex. The resulting vortex, according to Guinn and Schubert (1993), should be generally larger in horizontal extent and exhibit a spiral band of potential vorticity. The merger processes, which are essential in the potential vorticity theories, can involve the interaction of two tropical cyclones.

The interaction of two tropical cyclones is often referred to as the Fujiwhara effect. Fujiwhara (1921) introduced the concept of mutual cyclonic rotation followed by merger of two barotropic vortices. Chang (1983) suggested that the merger of vortices occurs as a result of boundary layer convergence and that diabatic effects are crucial. On the other hand, DeMaria and Chan (1984) argued that mergers can also occur in a barotropic model due to vortex propagation on the outer vorticity gradients associated with each vortex. The observational and theoretical aspects of tropical cyclone merger processes were further investigated in a series of papers by Dritschel and Waugh (1992), Dritschel (1995), Lander and Holland (1993), Ritchie and Holland (1993), Holland and Dietachmayer (1993), and Wang and Holland (1995).

Dritschel and Waugh (1992) and Dritschel (1995) described the general interaction of two unequally sized vortices in terms of the ratio of vortex radii and the dimensionless gap (defined as the distance between the edges of the vortices divided by the radius of the larger vortex). With these two parameters, two-vortex interactions can be classified into five regimes: 1) elastic interaction, 2) partial straining out, 3) complete straining 

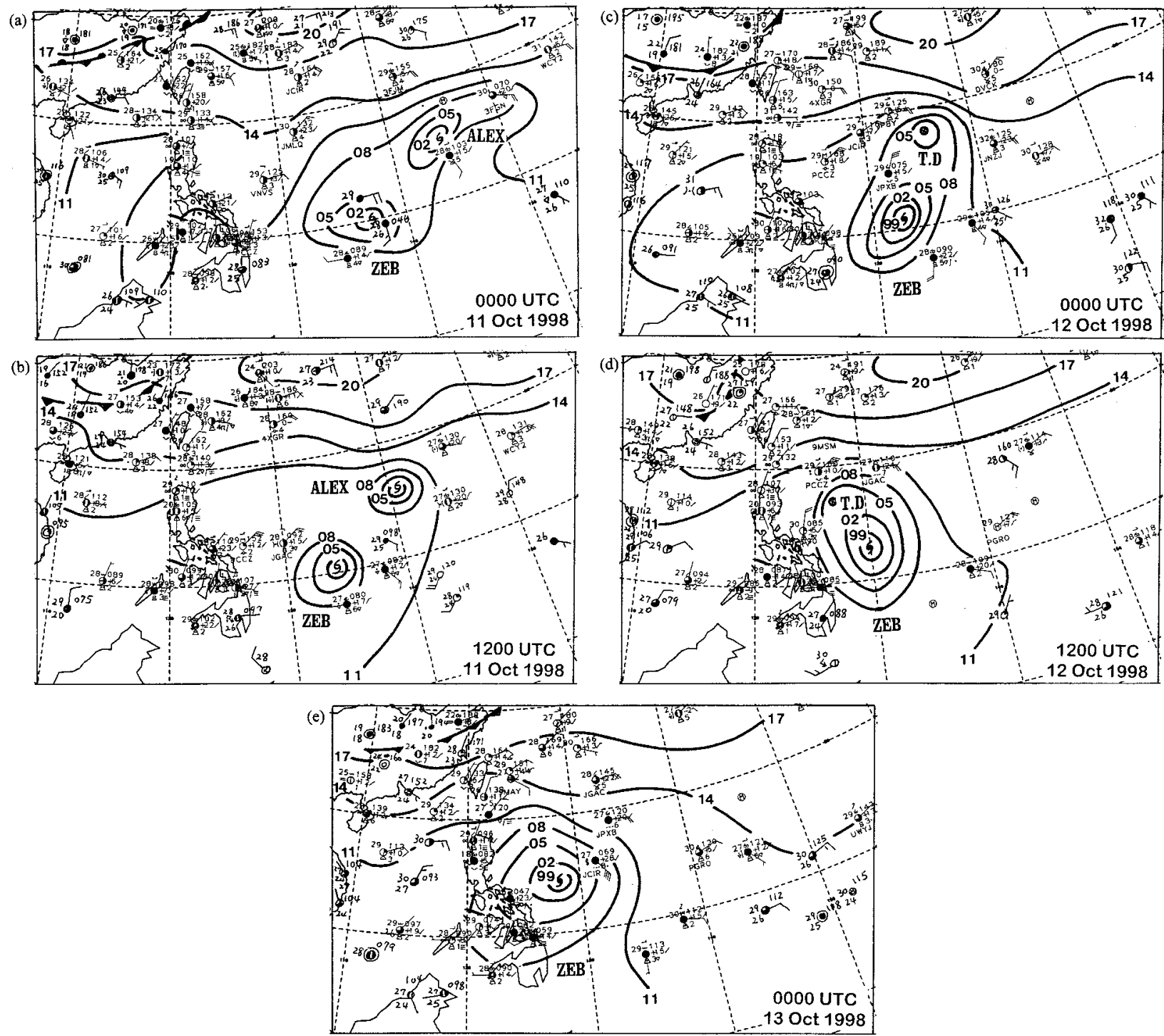

FIG. 1. Synoptic surface analyses at (a) 0000 UTC 11 Oct 1998, (b) 1200 UTC 11 Oct 1998, (c) 0000 UTC 12 Oct 1998, (d) 1200 UTC 12 Oct 1998, and (e) 0000 UTC 13 Oct 1998.

out, 4) partial merger, and 5) complete merger. The elastic interaction involves distortion to the vortices in a mutual cyclonic rotation. The merger regimes involve part of the smaller vortex being removed and some of it being incorporated into the larger vortex. The straining-out regimes involve part of the small vortex being removed and lost to filamentary vorticity with no incorporation into the larger vortex. The inelastic vortex interaction of unequal vortices without diabatic heating, as studied by Dritschel and Waugh (1992), does not always lead to vortex growth. The interaction of two vortices with a large difference in size results in part of the smaller vortex being torn away with no growth of the large vortex. In fact, in over half of the parameter space, smaller vortices are produced.

In the barotropic modeling study of Ritchie and Hol- land (1993), there were no gradients of vorticity apart from the discontinuities at the edge of the model vortices. Thus their results indicate that the attraction of two vortex patches during merger result entirely from changing advection as the vortices become distorted. This is in agreement with Guinn and Schubert (1993) and is different from the mechanisms proposed by Chang (1983) and DeMaria and Chan (1984). The baroclinic modeling work of Wang and Holland (1995) suggests that tropical cyclones must approach to within $450 \mathrm{~km}$ before their cores can merge. Wang and Holland (1995) also showed that rapid intensification occurs during merger and leads to a much more intense final vortex in the presence of diabatic heating.

Potential vorticity maps would be an ideal tool to analyze the merger of tropical cyclones. The absence of 

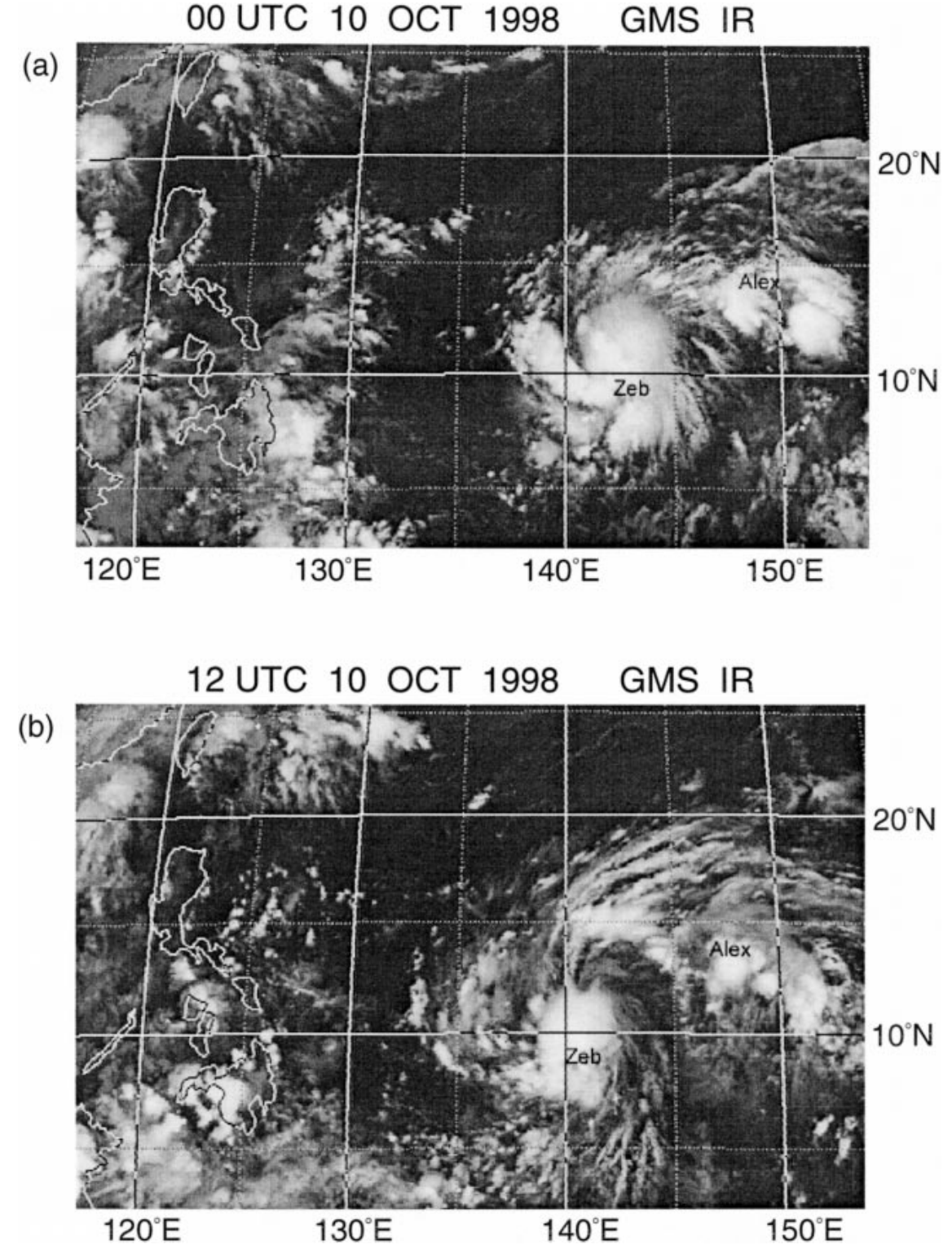

FIG. 2. Japanese GMS IR imagery at (a) 0000 UTC 10 Oct 1998, (b) 1200 UTC 10 Oct 1998, (c) 0000 UTC 11 Oct 1998, (d) 1200 UTC 11 Oct 1998, (e) 0000 UTC 12 Oct 1998, (f) 0600 UTC 12 Oct 1998, (g) 1200 UTC 12 Oct 1998, (h) 1800 UTC 12 Oct 1998, and (i) 0000 UTC 13 Oct 1998. Alex and Zeb are indicated.

simultaneous high quality three-dimensional wind and thermodynamic data prohibit researchers from producing observationally based, fine-grain potential vorticity maps of tropical cyclones (Shapiro and Franklin 1995). On the other hand, evidence of spiral bands formation in agreement with potential vorticity theories appear in the literature. An example of ITCZ breakdown and the formation of tropical cyclones and spiral bands can be seen in the series of satellite pictures presented by Agee (1972). The pictures show the connecting spiral cloud bands joining the tropical storms and the ITCZ. Lander (1995) has presented a western Pacific case that illustrates the loss of symmetry and subsequent merger of tropical cyclones Ruth and Pat. In this paper, we discuss the merger processes of Typhoons Zeb and Alex. Specifically, the mutual cyclonic rotation of Zeb and Alex and the filamentation of Alex into a spiral band of Zeb are presented. We also discuss the interaction of Alex and Zeb according to the flow regime of Dritschel and Waugh (1992). The merger processes are presented in section 2, and a summary is given in section 3 .

\section{The merger processes of two tropical cyclones}

To the east of Philippines during the first week of October 1998, the sea surface temperature (SST) was 

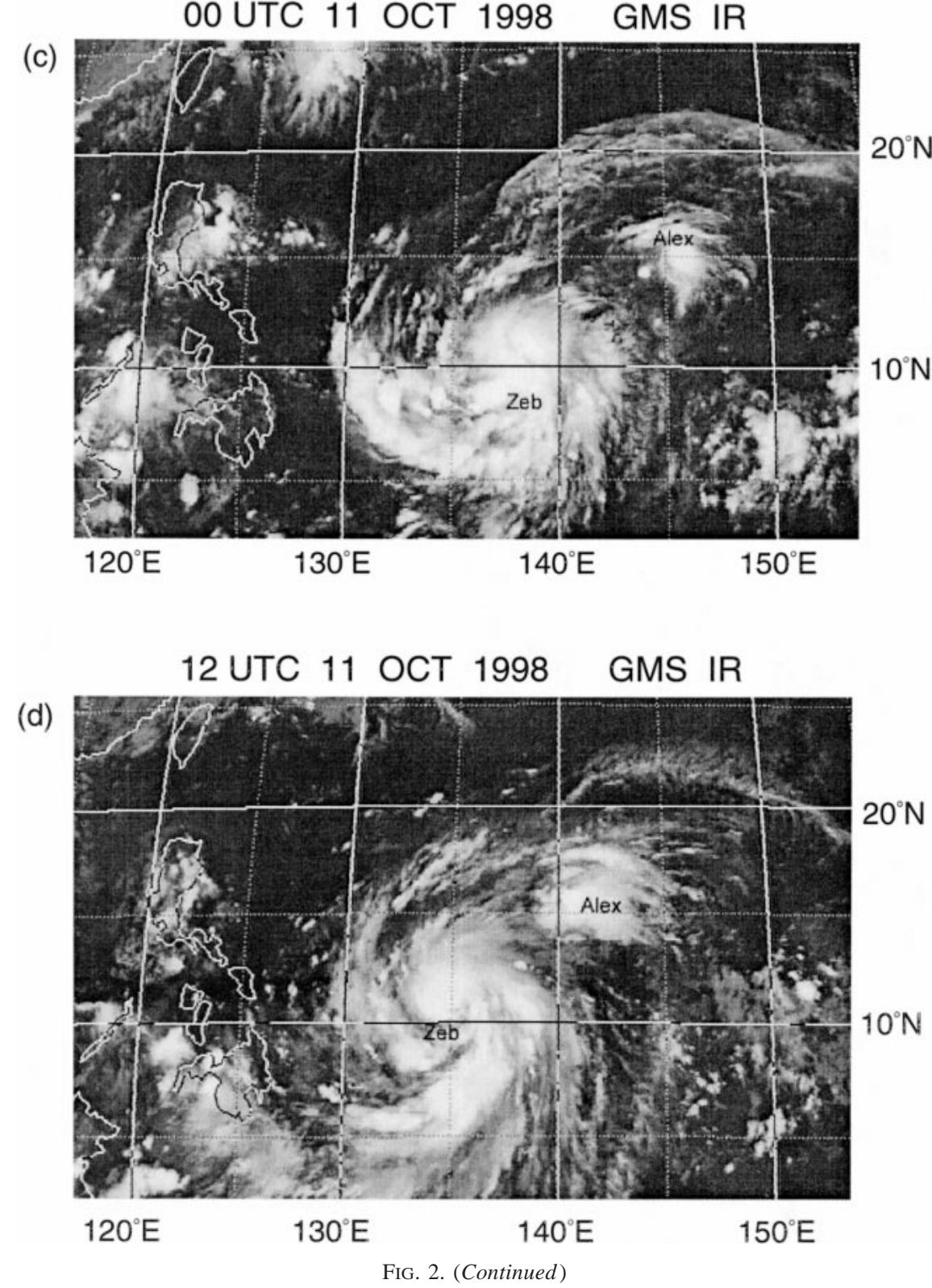

about $31^{\circ} \mathrm{C}$, well above that required for the formation of tropical cyclones. At 1800 UTC 9 October, two named tropical cyclones formed over this high SST area, with Zeb at $11^{\circ} \mathrm{N}, 143.5^{\circ} \mathrm{E}$ and Alex at $12.5^{\circ} \mathrm{N}, 151.5^{\circ} \mathrm{E}$. Figure 1 presents a sequence of five surface analyses beginning at 0000 UTC 11 October. The subtropical ridge was located near $29^{\circ} \mathrm{N}$, so that both Zeb and Alex moved westward in an easterly steering flow. Zeb developed during its westward journey, while Alex weakened gradually. The merger of Alex and Zeb took place shortly after 1800 UTC 12 October, after which the tracks become one.

Figure 2 shows Japanese Geostationary Meteorological Satellite (GMS) IR imagery from 0000 UTC 10
October to 0000 UTC 13 October 1998. The satellite pictures indicate that both Zeb and Alex exhibited organized cyclonic cloud systems. It appears that Alex was only slightly sheared by Zeb at 1200 UTC 11 October. After 0600 UTC 12 October, Alex was becoming further deformed by the circulation of Zeb and had advected to the north of Zeb. The distortion of the circulation of Alex at this time probably occurred more slowly than indicated by barotropic model studies (Dritschel and Waugh 1992), due to the tendency of diabatic heating to maintain the vortex against shearing deformation. Note that the convection to the west-southwest of Zeb had become weaker at this time (Fig. 2f). The weakening may be due to the possible influence of cool, 

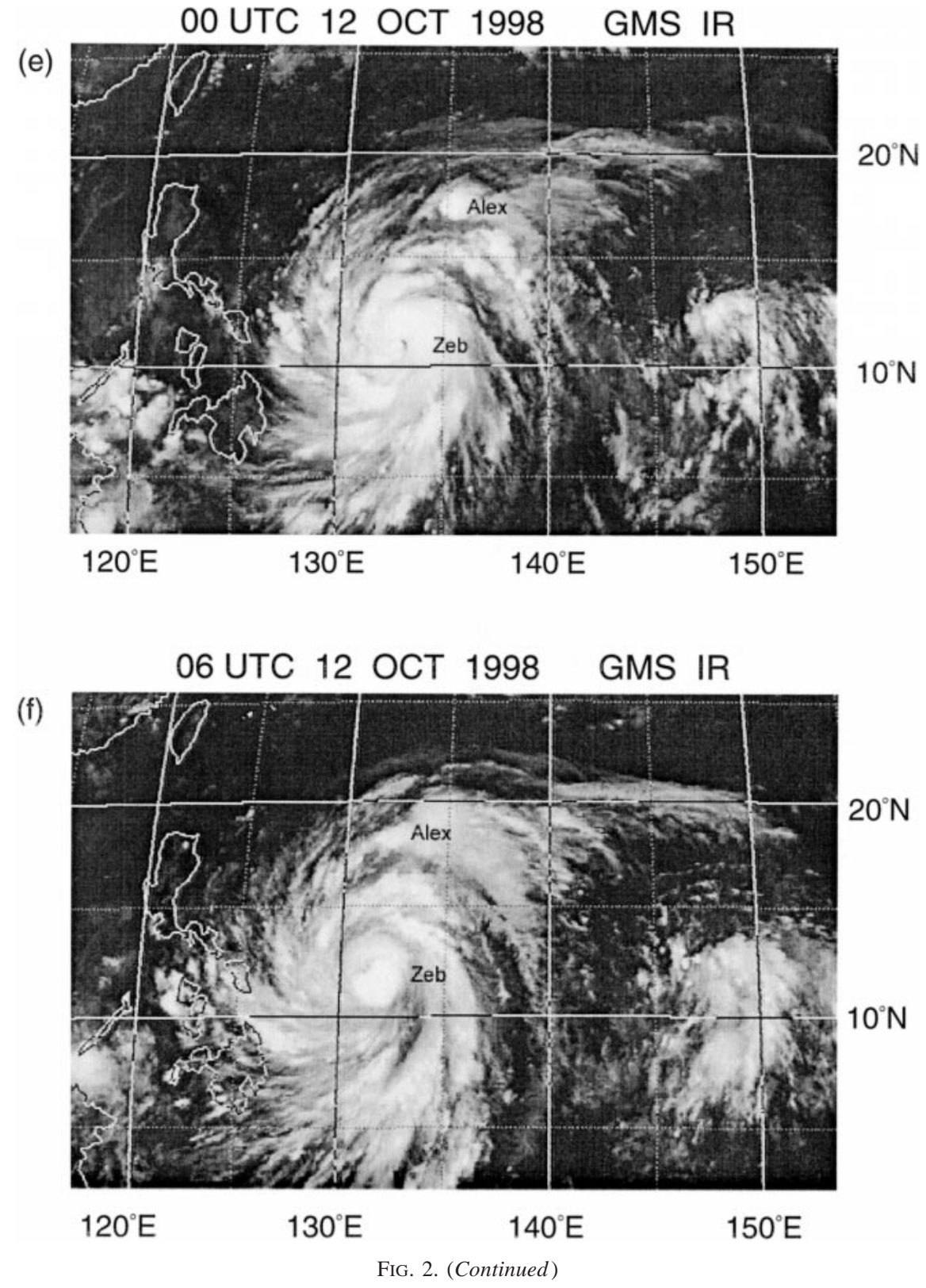

dry northeasterlies (e.g., Fig. 1d). In fact, it is often observed in satellite imagery at this time of the year that convection is weaker to the west of a tropical cyclone near the Philippines due to the cool, dry air entrained from the north. By 1200 UTC 12 October, Alex had been deformed into a spiral band and advected cyclonically around Zeb. Convection to the west of Zeb also reintensified. The elongation of Alex, followed by the stretching into a spiral band, is very similar to a simulation of Guinn and Schubert (their Fig. 9). At 1800 UTC 12 October (Fig. 2h) the most intense convection associated with Alex was approximately $480 \mathrm{~km}$ westnorthwest of Zeb. In addition, Zeb had developed a welldefined eye. By 0000 UTC 13 October (Fig. 2i) the convection associated with Alex appears as a spiral band in the southwest sector of Zeb, separated from Zeb's eyewall convection by a narrow clear region. It appears that the final stages of merger were occurring between 1800 UTC 12 October and 0000 UTC 13 October, although the spiral band, which was originally Alex, may never have mixed into the convective core of Zeb.

For the case of Alex and Zeb, a rough estimate of the ratio of vortex radii is approximately 0.2 and the dimensionless gap is approximately 0.6 at 1200 UTC 12 October. According to the flow regime diagram of Dritschel and Waugh (their Fig. 5), the interaction of Zeb and Alex at 1200 UTC 12 October should belong to the complete straining-out regime. The regime in- 

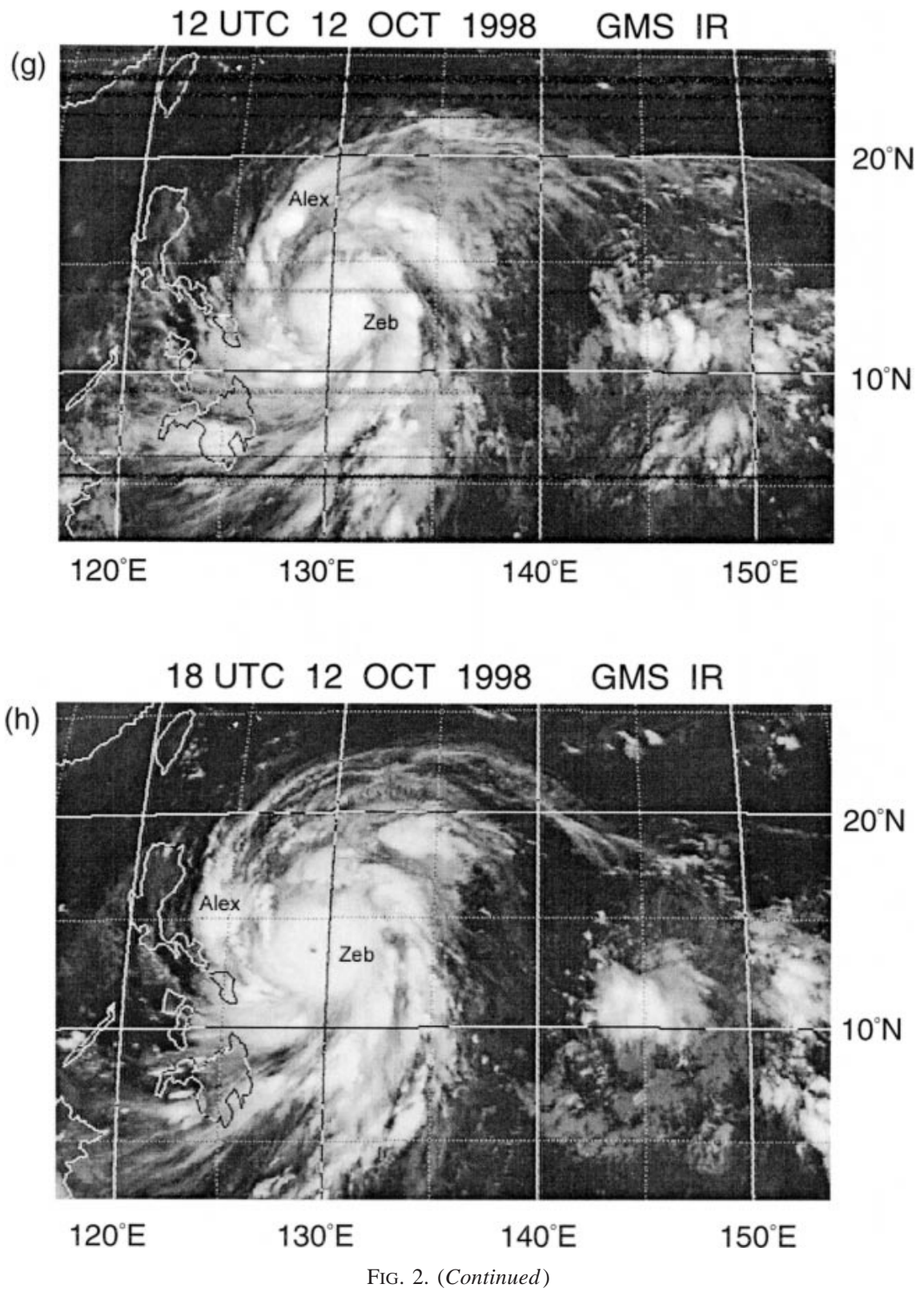

dicates that the small vortex is removed and lost to filamentary vorticity with no incorporation into the larger vortex. Eventually, the smaller vortex will be completely destroyed and the resultant configuration will consist of only the large original vortex. Despite the uncertainties in the observations, the image at 0000 UTC 13 October appears to be in general agreement with the theory.

Figure $3 \mathrm{a}$ displays the earth-relative best tracks of Alex and Zeb from 1800 UTC 9 October to 1800 UTC 12 October. The center positions are presented at 6-h intervals. The minimum pressures for Zeb, as estimated from the Dvorak technique by the Central Weather Bureau in Taiwan, are indicated next to Zeb. The minimum pressures for Zeb after merger are listed in the lower left corner of Fig. 3a. As indicated in this track analysis, Alex moved westward more rapidly than Zeb over the three days following formation. Zeb developed gradually from $1006 \mathrm{hPa}$ at 1800 UTC 9 October to $960 \mathrm{hPa}$ at 1800 UTC 12 October during its westward journey and intensified more rapidly from 960 to $920 \mathrm{hPa}$ within $24 \mathrm{~h}$ after merger. The rapid intensification of Zeb after merger is not without question. The maximum sustained surface winds estimated by the Joint Typhoon Warning Center indicates a deepening of $15 \mathrm{~m} \mathrm{~s}^{-1}$ in the $18 \mathrm{~h}$ after merger, which is no different from the deepening rate that occurred during the previous $36-\mathrm{h}$ period. Without detailed observations over the oceanic area near Zeb, 


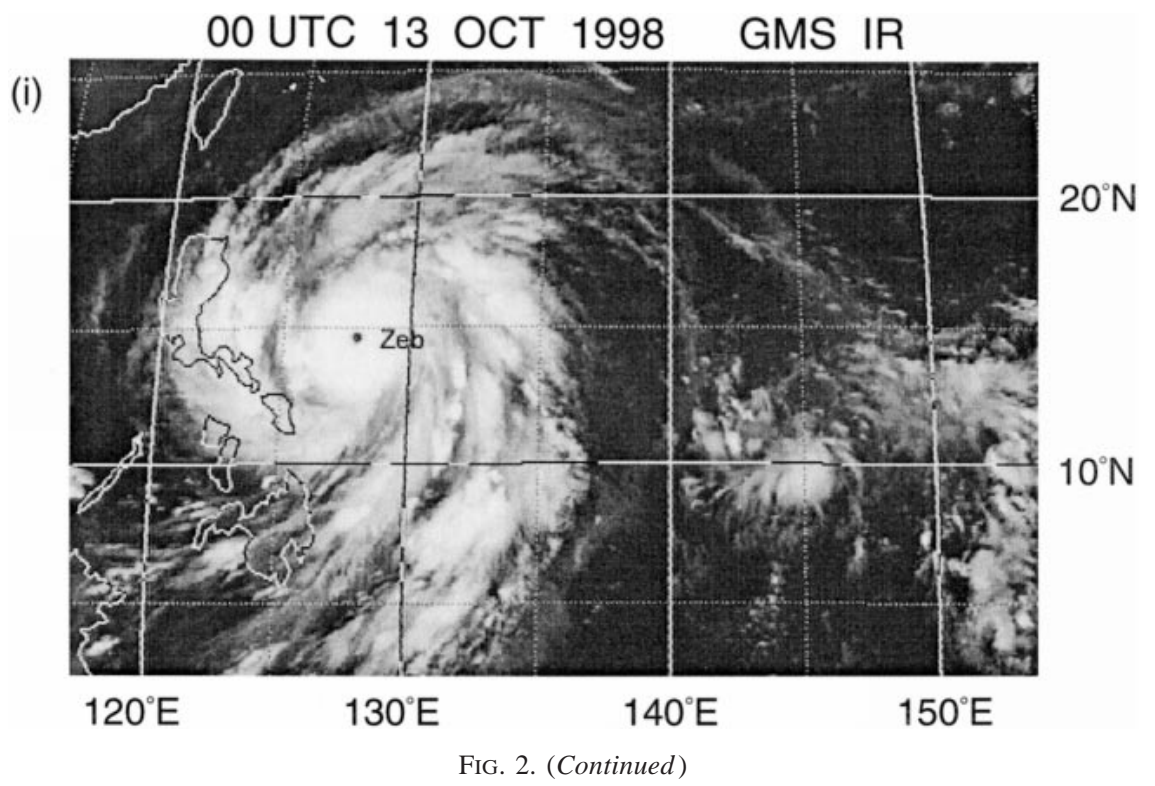

the central pressure, as well as the maximum sustained surface winds, are subject to some uncertainty. Upperlevel synoptic maps from the European Centre for Medium-Range Weather Forecasts (not shown) did not indicate any upper-level trough, nor any reduction of enviromental vertical shear near Zeb. Uncertainties in current intensity analysis make it difficult to diagnose how the interaction affected intensification. It has not been established whether intensification follows merger or is caused by merger. The causes for Zeb's intensification (or nonintensification) deserve further investigation. Our focus here is the merger processes of the two tropical cyclones. However, it is interesting to note that Zeb made landfall at Luzon and stalled there for approximately $12 \mathrm{~h}$. Zeb struck Taiwan on 16 October 1998 . It produced an average of $600 \mathrm{~mm}$ of rainfall in the northern part of Taiwan within $48 \mathrm{~h}$. The typhoon climatology of Taiwan from 1897 to 1992 indicates only a $7 \%-8 \%$ chance for landfalling typhoons with this strength during the month of October. Such an occurrence lends credence to the thesis that rapid intensification occurred following the absorption of Alex into the circulation of Zeb.

Figure $3 \mathrm{~b}$ displays the centroid-relative tracks. It reveals the mutual cyclonic rotation of Zeb and Alex from 1800 UTC 9 October to 1800 UTC 12 October. The distance between Zeb and Alex decreased from 900 to $450 \mathrm{~km}$ during this period. As seen in the surface analyses and satellite imagery in Figs. 1 and 2, Alex was smaller and weaker than Zeb. Since they are of unequal strength, we expect that Alex would rotate more rapidly than Zeb, and the centroid-relative track may not be the optimal way to represent the binary rotation. However, since the minimum pressure of Alex cannot be accurately analyzed on the synoptic map, we use both the centroid-relative track (Fig. 3b) and the Zeb-relative track (Fig. 3c) to indicate the binary rotation of the two cyclones. It is clear that Alex rotated cyclonically around Zeb and the rotation became faster after 0000 UTC 12 October, as Alex moved to within $850 \mathrm{~km}$ of Zeb. Alex could no longer be tracked after it approached within $450 \mathrm{~km}$ of the center of Zeb. Despite the fact that two unequal vortices are involved, the final merger distance is consistent with the baroclinic model results of Wang and Holland (1995).

\section{Summary}

We have documented the merger processes of tropical cyclones Zeb and Alex. These processes include mutual cyclonic rotation, followed by the complete straining out of Alex into a spiral band of Zeb. The cyclonic rotation of Alex around Zeb accelerated as the separation distance decreased to $850 \mathrm{~km}$. In the final stages of the interaction, Alex was quickly elongated and wrapped cyclonically around Zeb to become a spiral band of Zeb. It appears that the final stages of the interaction occurred at a distance of $450 \mathrm{~km}$, although the spiral band, which was originally Alex, may never have mixed into the convective core of Zeb. Zeb intensified from 960 to $920 \mathrm{hPa}$ within $24 \mathrm{~h}$ after merger. The formation of the spiral band in the merger process appears to be in good agreement with the vortex merger theories and formation of spiral bands by Dritschel and Waugh (1992), Guinn and Schubert (1993), Ritchie and Holland (1993), and Wang and Holland (1995). Despite the fact that two unequal vortices are involved, the merger distance is in good agreement with what baroclinic models suggest. The importance of diabatic effects during merger and the change of internal dynamics after merger have yet to be studied.

In closing we would like to point out that merger 


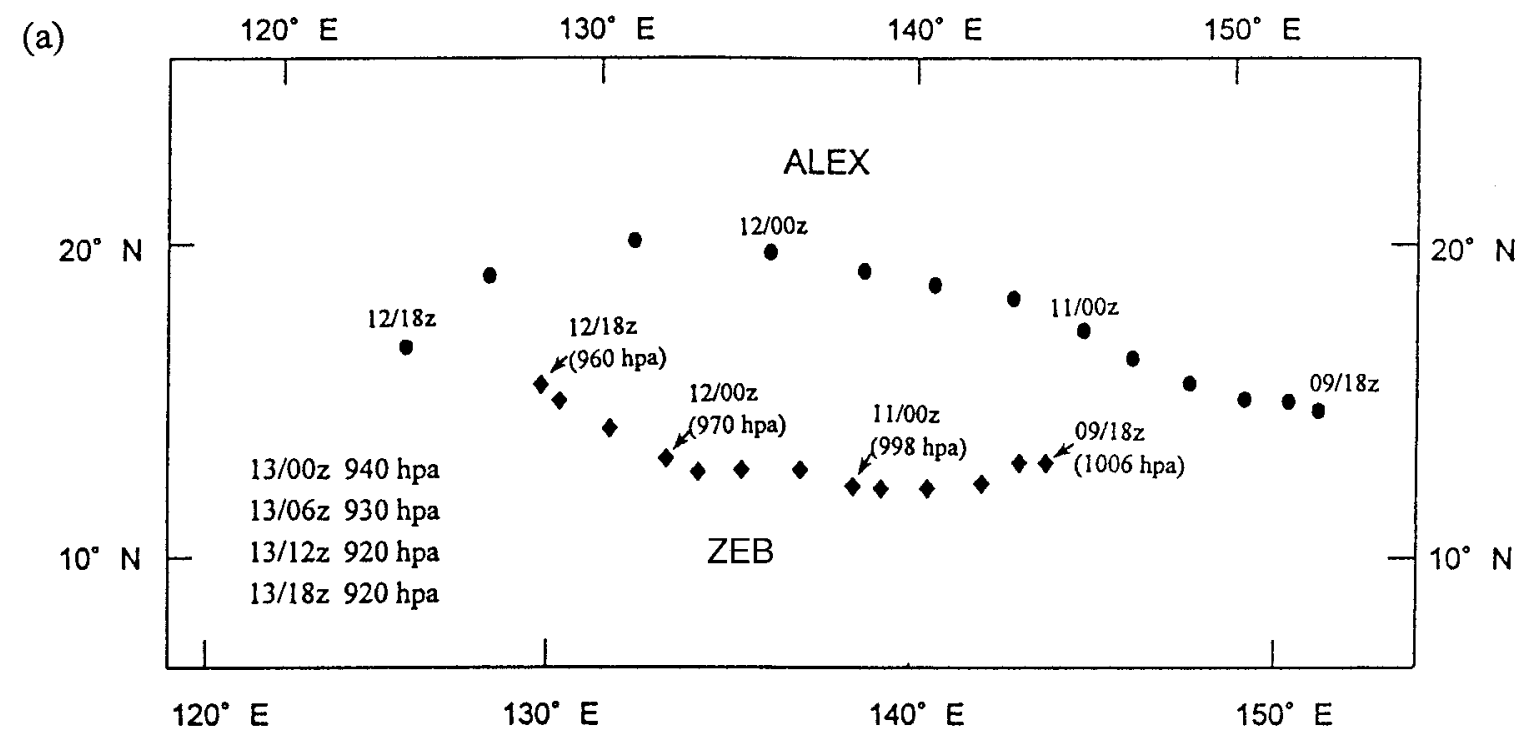

(b)

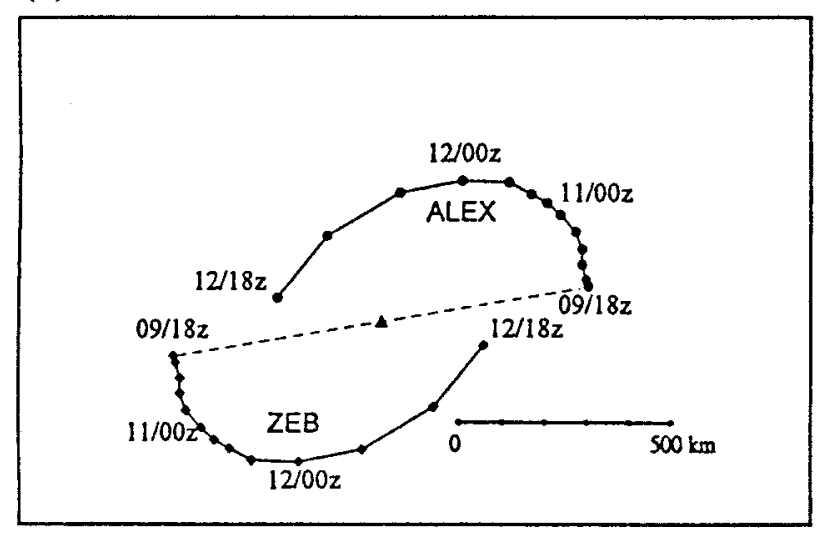

(c)

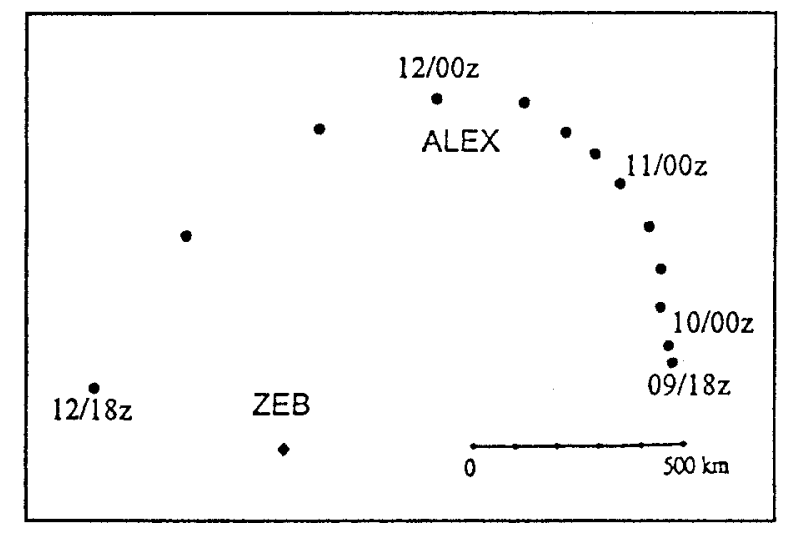

FIg. 3. Best tracks of Zeb and Alex: (a) earth-relative tracks, (b) centroid-relative tracks, and (c) Zeb-relative tracks. Black dots are at 6-h intervals. The minimum pressures of Zeb are indicated in (a).

processes may also be crucial on the mesoscale at the very early stages of tropical cyclone development. This has been discussed by Simpson et al. (1997) in their study of Tropical Cyclone Oliver during the Tropical Ocean Global Atmosphere Coupled Ocean-Atmosphere Response Experiment (1993). They observed the formation of midlevel, mesoscale potential vorticity anomalies, their subsequent merger, the associated downward development of cyclonic winds, and the formation of a nascent eye and inner rainbands. Thus, merger dynamics may be important to understanding all phases of the life cycle of tropical cyclones.
Acknowledgments. This research was supported by Grants NSC88-2111-M002-017 AP1, NSC88-2625Z002-029, and NSC89-2111-M-002-015 from the National Research Council of Taiwan and NSF ATM 9525755. We would like to thank two anonymous reviewers for their useful comments.

\section{REFERENCES}

Agee, E., 1972: Note on ITCZ wave disturbances and formation of tropical storm Anna. Mon. Wea. Rev., 100, 733-737.

Chang, S. W. J., 1983: A numerical study of the interaction between two tropical cyclones. Mon. Wea. Rev., 112, 1806-1817. 
DeMaria, M., and C. L. Chan, 1984: Comments on "A numerical study of the interactions between two tropical cyclones." Mon. Wea. Rev., 112, 1643-1645.

Dritschel, D. G., 1995: A general theory for two-dimensional vortex interactions. J. Fluid Mech., 293, 269-303.

— action of unequal vortices in two-dimensional vortex dynamics. Phys. Fluids A, 4, 1737-1744.

Fujiwhara, S., 1921: The mutual tendency towards symmetry of motion and its application as a principle in meteorology. Quart. J. Roy. Meteor. Soc., 47, 287-293.

Fung, I. Y.-S., 1977: The organization of spiral rain bands in a hurricane. Ph.D. thesis, Massachusetts Institute of Technology, $139 \mathrm{pp}$.

Guinn, T. A., and W. H. Schubert, 1993: Hurricane spiral bands. J. Atmos. Sci., 50, 3380-3403.

Holland, G. J., and G. S. Dietachmayer, 1993: On the interaction of tropical-cyclone-scale vortices. III: Continuous barotropic vortices. Quart. J. Roy. Meteor. Soc., 119, 1381-1398.

Kurihara, Y., 1976: On the development of spiral bands in a tropical cyclone. J. Atmos. Sci., 33, 940-958.

Lander, M. A., 1995: The merger of two tropical cyclones. Mon. Wea. Rev., 123, 2260-2265.

_ , and G. J. Holland, 1993: On the interaction of tropical-cyclone- scale vortices. I: Observation. Ouart. J. Roy. Meteor. Soc., 119, 1347-1361.

Montgomery, M. T., and R. J. Kallenbach, 1997: A theory for vortex Rossby-waves in its application to spiral bands and intensity changes in hurricane. Quart. J. Roy. Meteor. Soc., 123, 435-465.

— forced vortex Rossby waves in a three-dimensional quasigeostrophic model. J. Atmos. Sci., 55, 3176-3207.

Ritchie, E. A., and G. J. Holland, 1993: On the interaction of tropicalcyclone-scale vortices. II: Discrete vortex patches. Quart. J. Roy. Meteor. Soc., 119, 1363-1379.

Senn, H. V., and H. W. Hiser, 1959: On the origin of hurricane spiral bands. J. Meteor., 16, 419-426.

Shapiro, L. J., 1983: The asymmetric boundary layer flow under a translating hurricane. J. Atmos. Sci., 40, 1984-1998.

_ , and J. L. Franklin, 1995: Potential vorticity in hurricane Gloria. Mon. Wea. Rev., 123, 1465-1475.

Simpson, J., E. Ritchie, G. J. Holland, J. Halverson, and S. Stewart, 1997: Mesoscale interactions in tropical cyclone genesis. Mon. Wea. Rev., 125, 2643-2661.

Wang, Y., and G. J. Holland, 1995: On the interaction of tropicalcyclone-scale vortices. IV: Baroclinic vortices. Quart. J. Roy. Meteor. Soc., 121, 95-126.

Willoughby, H. E., 1978: A possible mechanism for the formation of hurricane rainbands. J. Atmos. Sci., 35, 838-848. 